\title{
A utilização da música no processo de humanização da assistência à pessoa com transtorno mental
}

\author{
Marco Aurélio Tosta Longo*, Silvia Andréia da Silveira*, Benedito Cherbéu Dlessandre Oliveira, M.Sc.**
}

${ }^{* *}$ Enfermeiros Hospital Psiquiátrico Américo Bairral, ${ }^{* *}$ Docente do Centro Universitário de Espírito Santo do Pinhal e Coordenador do Curso Técnico de Enfermagem da ETEC Pedro Ferreira Alves, Mogi Mirim/SP

\begin{abstract}
Resumo
Desde os tempos remotos, à música tem sido atribuído o mais diferente significado, seja em relação a sua expressão estética, ou a sua função mística, religiosa, mágica e terapêutica. Essas características conferem à música a capacidade de abranger o ser humano em sua totalidade, podendo ser utilizada no processo de humanização do cuidado de enfermagem. Este estudo teve como objetivo demonstrar os benefícios da música na humanização da assistência à pessoa com transtorno mental. A pesquisa de campo foi realizada entre os meses de julho e setembro de 2007 no Instituto Bairral de Psiquiatria, localizado na cidade de Itapira, interior do Estado de São Paulo, onde desenvolvemos atividades musicais junto a uma amostra de 27 sujeitos. Dentre os principais achados, notou-se que a música está diretamente relacionada à concepção de pensamentos e emoçóes positivas, favorecendo o relaxamento, a expressão de sentimentos, o resgate de memórias do passado e a melhoria do relacionamento interpessoal, contribuindo significativamente para o processo de humanização da assistência em saúde mental.
\end{abstract}

Palavras-chave: humanização, enfermagem, psiquiatria, música.

\section{Abstract \\ Music therapy to humanize assistance of people with mental disorder}

Since remote ages, it has been attributed different meaning to music, either in relation to the aesthetics expression, or to mystic, religious, magic and therapeutic function. It can be used as an instrument for humanizing the process of nursing care. This study had as objective to demonstrate the benefits of music to assistance of people with mental disorder and was carried out from July to September 2007 at Bairral Institute of Psychiatry, located in Itapira, São Paulo, where musical activities were developed with 27 persons. Among the main findings, it was observed that music was related directly to the conception of thoughts and positive emotions, favoring relaxation, expression of feelings, the recovery of past memories and interpersonal relationship improvement, contributing significantly for the process of humanization of mental health assistance.

Key-words: humanization, nursing, psychiatry, music. 


\section{Resumen}

\section{El uso de la música en el proceso de humanización de la asistencia a las personas con trastorno mental}

Desde tiempos remotos, el ser humano le ha atribuido a la música los más diferentes significados, sea en relación a su expresión estética o a su función mítica, religiosa, mágica o terapéutica. Esas características le dan la capacidad de abarcar al ser humano en su totalidad, siendo así utilizada en el proceso de humanización del cuidado de enfermería. Este estudio tuvo como objetivo demostrar los beneficios de la música en la humanización de la asistencia a las personas con trastorno mental. La investigación de campo fue realizada entre los meses de Julio a Septiembre de 2007 en el Instituto Bairral de Psiquiatría, ubicado en la ciudad Itapira, interior del Estado de São Paulo, donde desarrollamos actividades musicales junto a una muestra de 27 personas. Dentro de los principales puntos encontrados, notamos que la música está directamente relacionada a la concepción de pensamientos y emociones positivas, beneficiando el relajamiento, la expresión de sentimientos, el rescate de memorias del pasado y la mejora de relacionamientos interpersonales, contribuyendo significativamente para el proceso de humanización de la asistencia en la salud mental.

Palabras-clave: humanización, enfermería, psiquiatría, música.

\section{Introdução}

Sabe-se que a música abrange as dimensóes biológica, mental, emocional e espiritual do ser humano, entretanto muitos dos caminhos pelos quais isso ocorre ainda nos são desconhecidos. Independente disso observou-se ao longo da história da humanidade e da própria medicina sua utilização como recurso terapêutico [1].

A música é parte integrante da natureza e dos seres humanos. Seus componentes básicos, como o ritmo, a melodia e a harmonia, são os mesmos que compóem o nosso organismo, como, por exemplo, o ritmo cardíaco, a sincronização rítmica ao caminhar, a melodia e o volume de nossas vozes ao falar [2].

A música está enraizada nas camadas mais profundas da nossa personalidade, onde percepçóes sensoriais, sentimentos e pensamentos se integram [3]. Ela é uma forma de expressão não-verbal, percebida através do aparelho auditivo e posteriormente canalizada para o cérebro, para regióes de respostas emocionais, algumas delas associadas ao sistema límbico. A música ajuda a estimular a imaginação, a fantasia e a intuição, e assim, integrar as funçóes dos hemisférios direito e esquerdo do cérebro [4].

Estudos recentes indicam que quando ouvimos música, substâncias químicas cerebrais são liberadas, promovendo a regularização do humor, a redução da agressividade, a melhora de quadros depressivos [4], além de contribuir com a diminuição dos níveis elevados de estresse [5].

Nesse contexto, a presença do som ritmado e harmônico pode aliviar a dor de causa física e emocional, agir em parâmetros hemodinâmicos como freqüência cardíaca, pressão arterial, temperatura, bem como no relaxamento da pessoa com regularização do ritmo respiratório, relaxamento muscular e melhora do sono [6].

O presente trabalho tem como objetivo demonstrar os benefícios da música no processo de humanização da assistência à pessoa com transtorno mental.

$\mathrm{O}$ interesse pelo tema surgiu de nossa vivência como profissionais de saúde, e a partir da realização dos estágios onde convivemos com pessoas com transtornos mentais.

Com o processo da Reforma Psiquiátrica, que trouxe e ainda traz muitas inovaçóes para o tratamento ao "partilhante" portador de um transtorno mental, torna-se necessário que os profissionais de saúde mental se qualifiquem para as novas concepçóes e assim possam efetivar a assistência pautada em uma concepção de cidadania, ética, humanizaçáo e assistência integral [7].

$\mathrm{O}$ enfermeiro, na área psiquiátrica, pode dar sua contribuição para que a humanização da assistência torne-se possível, através de açóes que promovam mudanças na nossa prática de cuidar, desenvolvendo atividades que favoreçam o diálogo, a integração, a expressão de sentimentos, que são fatores importantes para um relacionamento interpessoal adequado entre o usuário do serviço e o profissional que presta os cuidados $[8,9]$.

A música, sendo uma linguagem universal, vem ao encontro dessa necessidade, uma vez que apresenta características capazes de atender o ser humano em sua totalidade, podendo ser utilizada na humanização da assistência em saúde mental. 
$\mathrm{O}$ interesse da enfermagem pela música como recurso no cuidado tem crescido e pode ser constatado nos estudos que apontam suas diversas contribuiçóes junto à pessoa sob seus cuidados, a exemplo da produçáo de conforto, da diminuição da dor e do favorecimento da comunicaçáo terapêutica, tornando o cuidado mais humanizado [10].

No Brasil, alguns hospitais já inseriram a música no processo de cuidar dos "partilhantes", sendo o Hospital Samaritano, o pioneiro na área da enfermagem. Nesse sentido, as enfermeiras das unidades dessa Instituição, prescrevem na Sistematização da Assistência de Enfermagem (SAE) a música como cuidado [11].

\section{Material e métodos}

O material para realização desta pesquisa obteve-se a partir da revisão bibliográfica de livros, teses, dissertaçóes e artigos publicados em periódicos localizados nas bases de dados Scielo, Lilacs e o acervo da Biblioteca da Unicamp, tendo como palavras-chave: humanização, enfermagem, psiquiatria e música.

Utilizou-se o método exploratório, descritivo e comparativo com abordagem qualitativa. $\mathrm{O}$ estudo desenvolveu-se entre os meses de julho a setembro de 2007, semanalmente, no período das 14 às 17 horas. Por tratar-se de uma experiência psiquiátrica, o trabalho foi realizado no Instituto Bairral de Psiquiatria, localizado na cidade de Itapira, interior do Estado de Sáo Paulo. A amostra foi composta de 27 sujeitos com idade entre 48 e 88 anos, com diagnósticos psiquiátricos e/ou neurológicos variados como depressão, doença de Alzheimer, transtorno de humor bipolar (THB), transtorno obsessivo compulsivo (TOC), esquizofrenia, Parkinson e alcoolismo. O grupo de "partilhantes" reunia-se no setor de Terapia Ocupacional, contando com a presença de uma terapeuta ocupacional responsável, onde eram desenvolvidas as sessóes de música por um período de 60 minutos. Para as sessóes utilizou-se instrumento de cordas (violáo), instrumentos de percussão (chocalho, pandeiro), e a voz em forma de cantar, possibilitando assim a participação mais direta dos integrantes do grupo. Optou-se por não selecionar um repertório específico, mas sim executar as músicas solicitadas pelos "partilhantes" valorizando o gosto musical de cada indivíduo. Mediante esse ambiente, fez-se uma série de observaçôes e registro das alteraçóes ocorridas relacionadas ao comportamento, expressóes faciais, frases ou palavras ditas, integraçáo entre o grupo e participação no canto das músicas.

Elaborou-se também, um questionário com perguntas semi-estruturadas que foram aplicadas individualmente para coleta e análise dos dados relacionados à atividade musical desenvolvida, sendo entrevistados três sujeitos no final de cada sessão, de um total de nove sessóes, perfazendo um número de 27 entrevistas. Foi optado por três sujeitos por sessão, pois não havia tempo hábil para se entrevistar todos em todas as sessôes. Os aspectos éticos da pesquisa foram preservados, pois o projeto foi aprovado pelo Comitê de Ética do Centro Universitário Regional de Espírito Santo do Pinhal. A categoria de análise escolhida foi a música na expressão de sentimentos, pois a coleta de dados se deu por entrevistas e informaçóes coletadas pelos entrevistados, baseados nos sentimentos e lembranças expressados pelos "participantes".

\section{Resultados e discussão}

Analisando os questionários obtidos, a amostra foi composta por 27 sujeitos, sendo 16 sujeitos do gênero feminino (59\%) e 11 sujeitos do gênero masculino (41\%) com faixa etária entre 48 e 88 anos.

A maioria dos "partilhantes" (37\%) tinha idade entre 60 e 69 anos. Esse fator mostrou-se relevante na escolha das músicas que foram utilizadas durante as sessóes, sendo que, geralmente, foram solicitadas cançóes antigas que marcaram época, como Carinhoso, Chalana, Asa Branca, Trem das Onze, algumas cantigas como Nesta Rua, Jardineira, e cançóes mais recentes como Aquarela, Porto Solidão, entre outras.

Em relação ao grau de escolaridade observou-se que a maior parte (59\%) dos "partilhantes" tinha o segundo grau completo.

Tabela I - Dados relacionados à preferência musical.

\begin{tabular}{lll}
\hline Variável & N & $\%$ \\
\hline Preferncia musical & & \\
\hline Sertanejo & 06 & 21,0 \\
Música clássica & 04 & 14,0 \\
Samba & 04 & 14,0 \\
Romântica & 04 & 14,0 \\
Religiosas/ vocacionais & 02 & 7,0 \\
MPB & 02 & 7,0 \\
Valsa & 02 & 7,0 \\
Tango & 01 & 4,0 \\
Bolero & 01 & 4,0 \\
Música portuguesa & 01 & 4,0 \\
Total & 27 & 100,0 \\
\hline
\end{tabular}

Fonte: Questionário elaborado pelos autores. 
A tabela acima demonstra o estilo musical que predominou entre os participantes do grupo. Percebe-se que os gêneros musicais são bastante variados, porém, o estilo predominante no grupo consultado foi o da música sertaneja (21\%).

Não houve relevância entre profissóes manuais e executivas. Elas eram bastante variadas, não formando com isto dados concretos que pudessem ser tabulados.

Dos 27, apenas 06 "partilhantes" (22\%) tinham algum conhecimento musical, e mesmo que atualmente não toquem nenhum instrumento, já estudaram música em alguma fase de suas vidas. Dos 06 "partilhantes" que escolheram a música sertaneja, 03 estudaram piano, 01 tocava acordeão e piano e 02 já tocaram violáo.

Durante as sessóes de música observou-se uma maior participação desses sujeitos, o que contribuiu para o envolvimento do restante do grupo no desenvolver das cançóes. Podemos citar o exemplo de um deles que pôde colaborar tocando um instrumento de percussão (chocalho), dando ritmo e fazendo com que as músicas ficassem mais alegres.

\section{Música na alteração do estado de humor}

Notou-se que a maioria dos "partilhantes" (56\%) refere sentir-se melhor após participar do grupo, demonstrando a capacidade da música em trazer bem-estar associado a seus aspectos positivos. Quanto ao seu significado, para (80\%) dos participantes, a música está diretamente ligada a sentimentos de alegria e contentamento.

A música é capaz de proporcionar distração, distanciando o "partilhante" dos pensamentos negativos, e uma vez a impressáo deixada na consciência, o humor deprimido pode ser substituído por pensamentos relacionados ao prazer, alegria, favorecendo sua ligaçáo com aspectos positivos que geram saúde [4].

Observa-se, porém, que algumas canções trazem maior emoção e alegria do que outras, especialmente se forem mais conhecidas pelos "partilhantes".

Carregada de afeto, a música só aparece com sentido ao sujeito a partir do momento em que ela apresenta um significado particular, pois uma mesma música não causa a mesma reação, o mesmo sentimento ou emoçáo em dois sujeitos diferentes [12].

Realmente pôde-se comprovar essa afirmação em nossa experiência prática, ao percebermos como cada indivíduo carrega consigo uma canção em particular, que certamente marcou um momento de sua vida e que é trazido à tona durante o tocar dessa canção. Vê-se na expressão (nos olhos) emocionada dos "partilhantes" o aflorar de muitos sentimentos embalados muitas vezes pelo simples tocar de uma melodia ou de uma letra conhecida.

\section{A música na expressão de sentimentos}

Alguns "partilhantes" definiram a música como algo que facilita a expressão de sentimentos internos. $\mathrm{Na}$ terapia musical os "partilhantes" acabam por encontrar um espaço geográfico e temporal para expressar seus sentimentos, sem nenhuma preocupaçáo com a técnica ou com o ter que se comunicar. Essa expressão pode se dar em nível musical, corporal e/ou verbal e, em grupo, possibilitar uma vivência rica, a ponto de partilhar com os outros sentimentos que lhes são comuns [12].

Em seu trabalho com música, realizado junto a "partilhantes" portadores da doença de Alzheimer e outros transtornos mentais na velhice, a comunicação não-verbal foi apontada como uma linguagem altamente significativa e merecedora de atenção [12].

\section{A música como forma de relaxamento}

Para outros “partilhantes", a música oferece um estado de relaxamento, tranqüilidade e paz.

$\mathrm{O}$ uso da música como um agente para o relaxamento e para o conforto espiritual, pode ser considerado um excelente subsídio para os tempos modernos, em que somos marcados pela busca de alternativas que contemplem a pessoa em sua integralidade [13].

A música afeta o corpo de duas maneiras distintas, diretamente com efeito do som sobre as células e os órgãos, e indiretamente agindo sobre as emoçôes, que depois, por seu turno, influenciam numerosos processos corporais, ocasionando relaxamento e bem-estar [14].

\section{Música e relacionamento interpessoal}

Quanto ao relacionamento interpessoal, a música também parece ter contribuído melhorando o diálogo entre os participantes, possibilitando que alguns dos "partilhantes" com dificuldade em estabelecer contato fossem estimulados a interagir com o grupo. 
Para 25 "partilhantes" (93\%) o grupo musical favoreceu as relaçóes, e somente 02 "partilhantes" (7\%) não se sentiram à vontade e permaneceram isolados durante as sessões.

As atividades grupais envolvendo a música favorecem a troca de experiências abrindo canais de comunicação por meio da linguagem não-verbal, quebrando barreiras psicológicas, facilitando o desenvolvimento das relaçóes interpessoais e despertando a sensibilidade para um olhar mais amplo do sujeito, buscando respeitá-lo em sua totalidade bio-psico-social e espiritual [15].

Como forma de comunicação, a música constitui uma das possibilidades de interação humana [3].

\section{A música como dispositivo de resgate do passado}

Outra possibilidade é a capacidade da música em evocar lembranças do passado, momentos vividos e pessoas a eles ligados.

Para 19 indivíduos (70\%) a música traz recordaçóes positivas, para $11(40 \%)$ lembranças dos familiares e amigos, para outros $10(37 \%)$ da infância e adolescência, para 05 (19\%) dos amores do passado, para 4 deles (14\%) recordaçôes negativas. Alguns "partilhantes" atribuíram mais de um tipo de recordação trazida pela audição musical.

A música mais que um dispositivo capaz de acessar memórias, mostra-se um instrumento apropriado para dar sentido à vida daqueles que estáo se sentindo incapacitados pela doença, possibilitando náo apenas a associação de lembranças, mas também o resgate de passagens de histórias pessoais e coletivas [12].

Através das cançóes de uma vida inteira, é possível relembrar momentos que, apesar de individuais, náo deixam de ser coletivos, que marcaram uma determinada fase da vida, uma geração, uma época [17].

A música tem sido apontada como um recurso valioso no tratamento das demências e como dispositivo que não apenas permite acessar as memórias, mas também, mantê-las acesas, mesmo que por pouco tempo [12].

\section{Os benefícios da música em grupo}

Quando perguntado aos “partilhantes” que participaram das sessóes de música se o grupo estaria trazendo algum benefício, obteve-se um número expressivo de 26 respostas positivas (sim) e apenas 01 resposta negativa (náo).
Assim, pode-se afirmar que existe um reconhecimento a respeito dos efeitos benéficos trazidos pela música no que se refere à sua utilização como forma de humanizar o cuidado ao "partilhante".

Em contrapartida obteve-se resposta negativa por parte de um dos participantes, que apesar de não reconhecer o benefício relata que a música lhe trouxe algo de especial.

Através de nosso estudo, observou-se que a música é capaz de proporcionar um ambiente alegre, descontraído e harmonioso, favorecendo o relaxamento e a expressão de sentimentos.

Durante as sessóes, puderam-se notar diferentes reaçóes por parte dos "partilhantes". Não raro, alguns deles se emocionavam no decorrer das cançóes demonstrando assim, a íntima ligação entre a música e os seus sentimentos.

A música permitiu aos "partilhantes" recordarem momentos de sua vida relacionados à família e amigos, então destacados pelos entrevistados como momentos que na maioria das vezes estáo ligados a lembranças prazerosas. A recordação foi expressa pelo próprios "participantes", pois eles eram pessoas preservadas.

Percebeu-se que alguns deles mais emotivos choraram recordando passagens alegres ou tristes da sua vida relacionadas a uma canção.

O relacionamento interpessoal entre "partilhante" e enfermeiro também foi favorecido com as sessóes de música em grupo, tornando o contato mais afetivo, sem que esse relacionamento deixasse de ser profissional.

Ao final das sessóes de música, o clima que prevalecia era de alegria: todos cantavam, batiam palmas, tocavam instrumentos, compartilhando entre o grupo suas experiências individuais e coletivas.

\section{Conclusão}

Neste estudo, buscou-se investigar os benefícios da música na psiquiatria, tendo como objetivo principal a humanização da assistência à pessoa com transtorno mental.

A motivação para realizar esta pesquisa surgiu do desafio em unirmos duas artes importantíssimas que se completam entre si: a arte do cuidar e a arte musical.

Considerando os achados obtidos, concluiu-se que a música apresenta características valiosas que podem ser utilizadas para o processo de humanização dos cuidados ao "partilhante", abrangendo os aspectos físico, emocional, espiritual e social. 
Com a realização deste trabalho, esperamos contribuir com a melhoria da assistência de enfermagem em saúde mental, demonstrando a importância da música como forma de humanização do cuidado, além de colaborar com dados que possibilitem, aos profissionais dessa área e de áreas correlatas, continuar pesquisando e aplicando procedimentos terapêuticos que melhor atendam às necessidades dos indivíduos com transtorno mental.

Por tratar-se de um assunto ainda pouco explorado, compartilhamos o entendimento de que mais pesquisas devem ser realizadas para um maior reconhecimento dos benefícios da música ao "partilhante" com transtorno mental.

\section{Referências}

1. Leão ER, Silva MJP. Música e dor crônica músculoesquelética: o potencial evocativo de imagens mentais. Rev Latinoam Enfermagem 2004;12(2):235-41.

2. Zárate PD, Díaz VT. Aplicaciones de la musicoterapia en la medicina. Rev Méd Chile 2001; 129(2):219-23.

3. Ruud E, ed. Música e saúde. São Paulo: Summus; 1991.

4. Giannotti LA, Pizzoli LML. Musicoterapia na dor: diferenças entre os estilos jazz e new age. Nursing (S. Paulo) 2004;71(7):35-41.

5. Viniegras CRVG, Rodríguez JM, Barbón DR, Echevarría NC. Musicoterapia. Una modalidad terapéutica para el estrés laboral. Rev Cuba Med Gen Integr 1997;13(6)538-43.

6. Hatem TP, Lira PIC, Mattos SS. Efeito terapêutico da música em crianças em pós-operatório de cirurgia cardíaca. J Pediatr 2006;82(3):186-92.
7. Villela SC, Scatena MCM. A enfermagem e o cuidar na área de saúde mental. Rev Bras Enfermagem 2004;57(6):738-41.

8. Andrade RLP, Pedrão LJ. Algumas considerações sobre a utilizaçáo de modalidades terapêuticas não tradicionais pelo enfermeiro na assistência de enfermagem psiquiátrica. Rev Latinoam Enfermagem 2005,13(5):737-42.

9. Inchoste AF, Mendes P, Fortes VLF, Pomatti DM. O uso da música no cuidado de enfermagem em hemodiálise. Nursing (S. Paulo) 2007;10(109):276-80.

10. Bergold LB, Alvim NAT, Cabral IE. O lugar da música no espaço do cuidado terapêutico: sensibilizando enfermeiros com a dinâmica musical. Texto e Contexto Enfermagem 2006;15(2):262-269.

11. Leão ER. Influência da música na saúde. Nursing (S. Paulo) 2007;104(9)

12. Aleixo MAR. Música - uma ponte no tempo: demência e memória musical [dissertação]. Rio de Janeiro: Pontifícia Universidade Católica do Rio de Janeiro, Departamento de Psicologia; 2004. 100f.

13. Backes DS, Ddine SC, Oliveira CL, Backes MTS. Música: terapia complementar no processo de humanização de uma CTI. Nursing (S. Paulo) 2003;66(6):37-42.

14. Tame D. O poder oculto da música. Sáo Paulo: Citrix; 1984.

15. Pimentel AF. Convergências entre a política nacional de humanização e a musicoterapia [monografia]. Rio de Janeiro: Escola Nacional de Saúde Pública Sérgio Arouca; 2005.

16. Bergold LB, Sobral V. Como uma onda no ar: a música na humanização dos cuidados. Online Brazilian Journal of Nursing 2003;2(3).

17. Souza MGC. Musicoterapia e a clínica do envelhecimento. In: Freitas EV, Py L, Nery AL. Tratado de Geriatria e Gerontologia. Rio de Janeiro: Guanabara Koogan; 2002. p. 872-81. 